\title{
EVALUATION OF THE SOIL MOISTURE AGRICULTURAL DROUGHT INDEX (SMADI) AND PRECIPITATION-BASED DROUGHT INDICES IN ARGENTINA
}

\author{
M. M. Salvia ${ }^{1, *}$, N. Sánchez ${ }^{2}$, M. Piles ${ }^{3}$, A. Gonzalez-Zamora² ${ }^{2}$ J. Martínez-Fernández² \\ ${ }^{1}$ Quantitative Remote Sensing Group, Instituto de Astronomía y Física del Espacio (IAFE, UBA/CONICET), Intendente Güiraldes \\ 2160, Ciudad Universitaria, C1428EGA, CABA, Argentina - msalvia@iafe.uba.ar \\ ${ }^{2}$ Instituto Hispano Luso de Investigaciones Agrarias (CIALE). University of Salamanca. Duero 12, 37185 Villamayor, Salamanca, \\ Spain - (nilda, aglezzamora,jmf)@usal.es \\ 3 Image Processing Laboratory, IPL, Universitat de València, 46980 Valencia, Spain - maria.piles@uv.es
}

KEY WORDS: soil moisture, precipitation, agricultural drought, SMOS, SMADI, SPI, SPEI.

\begin{abstract}
:
Agricultural drought is one of the most critical hazards with regard to intensity, severity, frequency, spatial extension and impact on livelihoods. This is especially true for Argentina, where agricultural exports can represent up to $10 \%$ of gross domestic product (GDP), and where drought events for 2018 led to a decrease of nearly $0.5 \%$ of GDP. In this work, we investigate the applicability of the Soil Moisture Agricultural Drought Index (SMADI) for detection of droughts in Argentina, and compare its performance with the use of two well-known precipitation-based indices: the Standardized Precipitation Index (SPI) and the Standardized PrecipitationEvaporation Index (SPEI). SMADI includes satellite-based information of soil moisture, surface temperature and vegetation greenness, and was designed to capture the hydric stress on the soil-vegetation ensemble. Results indicate that SMADI has greater capabilities for agricultural drought detection than SPI and SPEI: it was able to recognize more than $83 \%$ of the registered emergencies, correctly classifying $75 \%$ of them as extreme droughts, and outperforming SPI and SPEI in all the analyzed metrics.
\end{abstract}

\section{INTRODUCTION}

Agricultural drought is one of the most critical hazards with regard to intensity, severity, frequency, spatial extension and impact on livelihoods. In the last decades, the occurrence of drought episodes is increasing, with direct and indirect impacts on economy, environment and food security (Foley et al., 2011). This is especially true for Argentina, where agricultural exports can represent up to $10 \%$ of gross domestic product (GDP) (Pisani-Claro and Miazzo, 2017), and where drought events for 2018 led to a decrease of nearly $0.5 \%$ of GDP (Lema, Amaro and Pace, 2018).

According to the IPCC (IPCC, 2014), there are three main types of drought, depending on which part of the hydrological system suffers from water deficit: 1) meteorological drought, which is associated with a deficit in precipitation, 2) hydrological drought, that occurs when there is a low water supply in streams, reservoirs, and groundwater levels, usually after many months of meteorological drought, and 3) agricultural drought (also known as soil moisture drought), which is associated with a deficit of water in the soil's unsaturated zone that could compromise the crop yields. Since a precipitation deficit propagates through the system into (potentially) soil moisture and streamflow anomalies, drought types are inherently related between them. Probably for this reason, precipitation-based indices are often used for detection of agricultural drought, together with the wide availability of meteorological databases. However, the processes involved in the evolution of droughts are complex (Barella-Ortiz et al., 2018), specially over agroecosystems, where the deficit in plant-available water that could compromise crop production depends on the type of crop, its location, and season. Hence, precipitation-based indices, yet simple and widely used, may not be the most suitable indicators for detection of agricultural drought. Alternatively, the use of readily available satellite-based soil moisture estimates to improve early detection of agricultural drought is a promising venue of current research (e.g. MartínezFernández et al., 2016, Mishra et al., 2017, Pablos et al., 2017, Sánchez et al., 2018).

In this work, we investigate the applicability of the Soil Moisture Agricultural Drought Index (SMADI) for detection of droughts in Argentina, and compare its performance with the use of two well-known precipitation-based indices: the Standardized Precipitation Index (SPI) and the Standardized PrecipitationEvaporation Index (SPEI). SMADI is a simple and intuitive index that allows determining agricultural drought events based on the physical conditions of the soil-vegetation ensemble. As a distinct feature with respect to other soil-moisture based drought indices, SMADI also includes information on the vegetation status and encodes a delayed impact of drought on the vegetation ensemble.

SMADI is solely based on remote sensing datasets of Surface Soil Moisture (SSM), Land Surface Temperature (LST), and Normalized Difference Vegetation Index (NDVI). Previous experiments with SMADI in the Iberian Peninsula (Sánchez et al., 2016) and at continental and global scales (Sánchez et al., 2018), showed a reasonable match with other climaticagricultural indices and with registered events of drought.

The document is structured as follows. In Section 2 we first introduce the three indices, their rationale and how they have been calculated for this study. Following a characterization of the study area and a description of the agrarian emergencies database, the validation metrics and main results of our analysis are shown and discussed in Section 3. Conclusions and perspectives from this work are given in section 4 .

* Corresponding author 


\section{DATA AND METHODS}

\subsection{SMADI, SPI, SPEI}

2.1.1 SMADI: SMADI is a soil-moisture based index aimed to detection and monitoring of agricultural drought. Together with soil moisture information, it further embeds a descriptor of vegetation's photosynthetic activity (Normalized Difference Vegetation Index, NDVI) and the land surface temperature (LST), in an attempt to jointly describe the status of the soil-plant continuum. All the variables are obtained from remote sensing sources, and it is scalable both in space and time.

The rationale of SMADI is based on the inverse relationship between the LST and vegetation status, which is, in turn, related to the soil moisture content (Carlson et al., 1994). First, each variable is normalized in the form of a "condition index", after Kogan $(1990,1995)$, using the maximum and the minimum time range values for each (eqs. 1, 2 and 3).

$$
\begin{gathered}
V C I=\frac{\left(N D V I_{i}-N D V I_{\min }\right)}{\left(N D V I_{\max }-N D \min \right)}(1), \quad M T C I=\frac{\left(L S T_{i}-L S T_{\min }\right)}{\left(L S T_{\max }-L S T_{\min }\right)}(2), \\
S M C I=\frac{\left(S M_{\max }-S M_{i}\right)}{\left(S M_{\max }-S M_{\min }\right)}
\end{gathered}
$$

where $\mathrm{i}$ corresponds to a given biweekly period. Then, SMADI computes the ratio between the temperature condition index and the vegetation condition index multiplied by the soil moisture condition index (eq. 4). Since there is a lag between the plant response and the atmospheric/soil factors, a certain time lag between the NDVI and the LST/SSM should be considered.

$$
S M A D I_{i}=S M C I_{i} \frac{M T C I_{i}}{V C I_{i+1}}
$$

The VCI for a given i corresponds to the ensuing fourteen-day period. This time lag is imposed to consider the lag between the plant response and the soil moisture conditions, following previous experiences with SMADI. Following Sanchez et al. (2018), the raw values of SMADI were classified into five intensity categories (Table 1):

\begin{tabular}{|c|c|c|c|c|c|}
\hline & $\begin{array}{c}\text { Non- } \\
\text { drought }\end{array}$ & $\begin{array}{c}\text { Pre- } \\
\text { drought }\end{array}$ & Moderate & Severe & Extreme \\
\hline SMADI & $0-0.999$ & $1-1.999$ & $2-2.999$ & $3-3.999$ & $\geq 4$ \\
\hline
\end{tabular}

Table 1. Drought categories after SMADI

The global datasets included in SMADI are the daily MODIS/Terra LST (MOD11C1 v.6), the daily reflectance (MOD09CMG v.6, from which NDVI was computed), and the daily SMOS L3 soil moisture (BEC v2.0, Barcelona Expert Center, 2019). All of them are integrated in SMADI at a spatial resolution of $0.05^{\circ}$ and a biweekly temporal rate. SMADI was calculated only for grassland and cropland areas, as indicated by the MODIS/Terra Land Cover Types map (MOD12C1). A more detailed description of the SMADI basis and its calculation can be found in Sánchez et al. (2018).
2.1.2 SPI and SPEI: The SPI (McKee et al., 1993) is based on the conversion of precipitation data to probabilities based on long-term precipitation records computed at different time scales (Scaini et al., 2015). Drought is related to standardized precipitation series, which is the difference of precipitation from the mean for a specified time period divided by the standard deviation (McKee et al., 1993). But since precipitation is typically not normally distributed, different probability models should be used to fit the precipitation series. Here, a gamma distribution function was applied (Podestá et al., 2016), a reference period of 40 years was used (1971-2010), and a onemonth temporal scale of SPI was selected in order to match the SMADI temporal rate.

The SPEI (Vicente-Serrano et al., 2010) is mathematically similar to the standardized precipitation index, but adds to the precipitation series the reference evapotranspiration (therefore, the role of temperature) and involves a climatic water balance and the accumulation of deficit/surplus. As for SPI, a monthly series of SPEI was used.

Both the SPI and SPEI data used in this research was provided by the Regional Climate Center Network for Southern South America (CRC-SAS, 2019) at a spatial resolution of $0.5^{\circ}$.

Following Keyantash et al., (2018), the raw values of SPI and SPEI were classified into four intensity categories (Table 2):

\begin{tabular}{|l|l|l|l|}
\hline Normal or wet & Moderately Dry & Severely Dry & Extremely Dry \\
\hline SPI $>-1$ & $-1 \geq$ SPI $>-1.5$ & $-1.5 \geq$ SPI $>-2$ & SPI $\leq-2$ \\
\hline
\end{tabular}

Table 2: Drought categories after SPI and SPEI.

\subsection{Study area and emergency declarations}

Argentina is located at the southernmost part of the American Continent. It has a continental surface of $2,791,810 \mathrm{~km}^{2}$ and expands from $21^{\circ} 46^{\prime} 52^{\prime \prime} \mathrm{S}$ to $55^{\circ} 03^{\prime} 21^{\prime \prime} \mathrm{S}$, and from $53^{\circ} 38^{\prime} 15^{\prime \prime}$ $\mathrm{W}$ to $73^{\circ} 34^{\prime} \mathrm{W}$ (IGN, 2019). It has a wet-to-dry gradient from $\mathrm{NE}$ to $\mathrm{SW}$ ranging from $1800 \mathrm{~mm}$ to $50 \mathrm{~mm}$ mean annual precipitation, and an annual mean temperature which spans from $22^{\circ} \mathrm{C}$ to $6^{\circ} \mathrm{C}(\mathrm{SMN}, 2019)$

It includes the southern part of La Plata Basin (the second largest basin of the continent), and the Pampas plains. These two subregions house large population densities, and have high productivity of agriculture and cattle raising. Since Argentina's economy has historically been highly dependent of its agricultural exports, drought detection and forecasting is paramount and a central issue for the country.

In this line, when a drought affects productive activities, the Argentina Ministry for Agriculture (in its different forms and names) declares an agrarian emergency, and that allows producers to get a refund for their taxes. These declarations are made at the spatial scale of departments within a province, and at a temporal scale that usually includes the whole productive cycle affected (even if the drought only covered part of the cycle). They are often declared within the same productive cycle, but months after the drought has started. This last characteristic makes them of no value for forecasting purposes.

Resolutions of the Ministry of Agriculture are public and can be found online (MAGyP, 2019). Fig. 1 shows the number of drought emergencies declared at the department scale for the 2010-2015 period. 
In order to evaluate SMADI, SPI and SPEI performances in Argentina for the period covering June 2010 to December 2015, we downloaded and digitized every declaration of drought emergency reported during this period. For each emergency declared, we then aggregated all departments involved on that particular emergency for each province. This gave us a total of 49 emergencies, which were divided in 6 years, according to their start date (6 starting from June to December of 2010, 19 starting in 2011, 8 starting in 2012, 12 starting in 2013, 4 starting in 2014 and none starting in 2015).
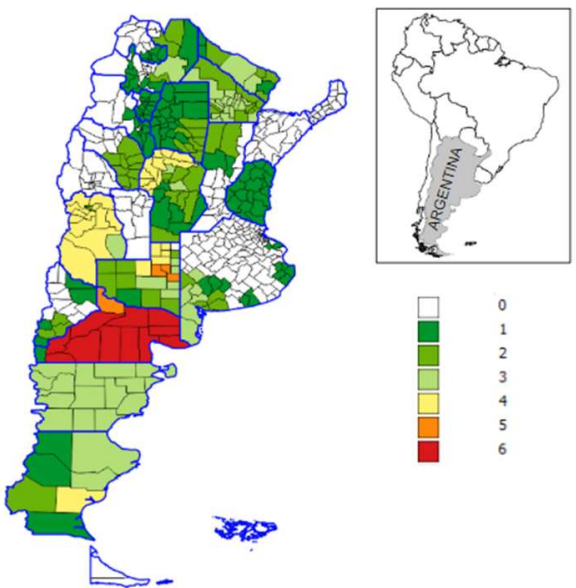

Figure 1. Number of drought emergencies declared (at the department scale). Blue lines represent Province limits. Black lines represent Department limits.

\subsection{Validation metrics}

For validation purposes, we used an inclusive time schedule. This means that we considered a SMADI (SPI or SPEI) period to be part of the emergency declaration timeframe if at least one day of the emergency was included in that period.

Following Sanchez et al. (2018), for each emergency declaration, the following validation metrics have been used:

- Extension: percentage of emergency area that shows any drought category (pre-drought to extreme categories for SMADI, moderately dry to extremely dry for SPI and SPEI). For SMADI a match is considered if there is at least $1 / 3$ of the emergency area for two consecutive dates (28 days) with a SMADI $\geq 1$. For SPI and SPEI a match is considered if there is at least $1 / 3$ of the emergency area with SPI or SPEI $\leq-1$ for any single period (1 month)

- $\%$ duration: percentage of emergency period that is considered a match for SMADI, SPI, or SPEI. For the yearly calculations, an average of duration is computed.

- Extreme 0: number of emergencies that have at least one pixel with an extreme category $(\mathrm{SMADI} \geq 4.0, \mathrm{SPI}<-2.0$, SPEI $<-2.0)$.

- Extreme 33: number of emergencies that have at least $1 / 3$ of their area covered by the extreme category of the studied index $(\mathrm{SMADI} \geq 4.0, \mathrm{SPI} \leq-2.0, \mathrm{SPEI} \leq-2.0)$.

Validation metrics were computed both at yearly basis and for the whole studied period. In the latter case, all emergencies were pooled together regardless of the occurrence year to grant them the same weight in calculations; note that yearly results were not used for the total calculation to avoid providing less weight to emergencies from the years with the highest number of reported emergencies and vice-versa.

\section{RESULTS}

As detailed in section 2.2, we have analysed a total of 49 drought emergency events declared between June 2010 and December 2014 (see Fig. 1).

Figure 2 shows, as an example, the drought emergency declared between July, 1st, 2013 and December 31st, 2013 for a part of Santa Fe Province, as seen by the three indices for the same observation period: August, 2013 for SPI and SPEI, and the period between August 13 and August 26, 2013.

This particular emergency not only was detected by the three indices, but they also coincide in at least one of the detected periods. For this particular emergency, SMADI shows matches in 6 consecutive 14-day observation periods (out of 14 included periods) covering the whole time lapse between July 31 st and November 4th. SPI showed a match only for August, 2013, and SPEI showed matches for August and December 2013. As a result, the three indices coincide in the detection for the month of August.

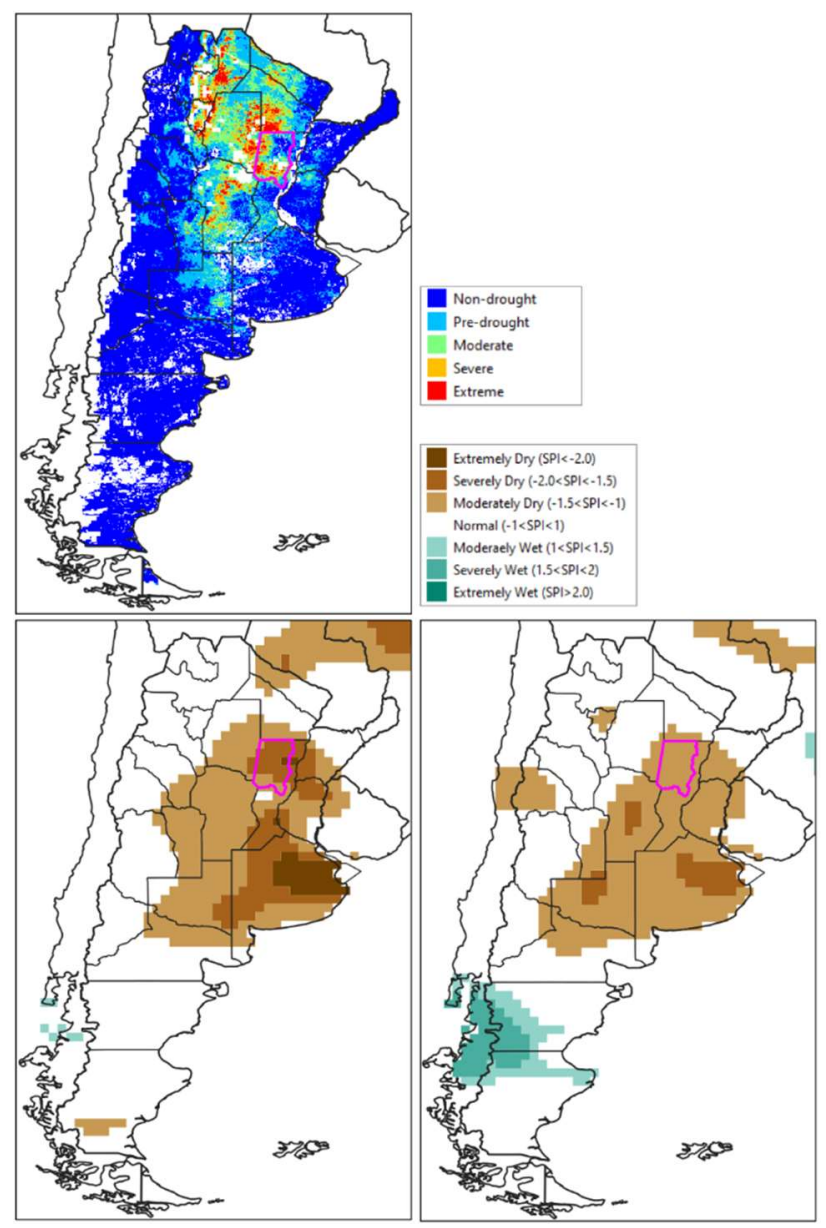

Figure 2: Illustration of detection capabilities for the emergency declared between 01-Jul-2013 and 31-Dec-2013. Top: SMADI results for period August 13th - 26th, 2013. Bottom left: SPI results for August, 2013. Bottom right: SPEI results for August, 2013. In all cases, the magenta polygon represents the area of the emergency, and black thin lines represent province limits. 
Table 3 shows the validation metrics for SMADI. Considering the whole study period, SMADI allows for reasonably good detection capabilities when taking into account the extension of different drought classes ( $83.7 \%$ of matches) and the presence of extreme values in those matches (75.5\% matches of Extreme_0).

The results involving drought duration are however considerably lower $(31.6 \%$ match). This can partially be explained by the nature of the emergency declarations, which fixes the way their temporal scale is registered: since the Ministry's goal is to generate tax refunds for affected producers, emergencies are declared for the entire affected productive cycle (with a different length for crops, cattle raising, etc.). Since a drought does not necessarily need to persist all along the productive cycle to affect crop yield (e.g. a drought during crop early growthdevelopmental stages only can have the highest impact), temporal coverage for a drought is usually overestimated in emergency declarations.

\begin{tabular}{|c|c|c|c|c|c|c|}
\hline & 2010 & 2011 & 2012 & 2013 & 2014 & Total \\
\hline $\begin{array}{l}\text { Drought } \\
\text { events }\end{array}$ & 6 & 19 & 8 & 12 & 4 & 49 \\
\hline $\begin{array}{l}\text { SMADI } \\
\text { matches }\end{array}$ & 5 & 15 & 8 & 12 & 1 & 41 \\
\hline $\begin{array}{l}\% \text { correct } \\
\text { matches }\end{array}$ & 83.3 & 78.9 & 100 & 100 & 25 & 83.7 \\
\hline$\%$ duration & 33.4 & 28.2 & 29.8 & 36.4 & 30.8 & 31.6 \\
\hline $\begin{array}{l}\text { SMADI } \\
\text { Extreme_0 }\end{array}$ & 5 & 12 & 7 & 12 & 1 & 37 \\
\hline $\begin{array}{l}\% \text { SMADI } \\
\text { Extreme_0 }\end{array}$ & 83.3 & 63.2 & 87.5 & 100 & 25 & 75.5 \\
\hline $\begin{array}{l}\text { SMADI } \\
\text { Extreme_33 }\end{array}$ & 0 & 0 & 3 & 4 & 0 & 7 \\
\hline $\begin{array}{l}\text { \% SMADI } \\
\text { Extreme_33 }\end{array}$ & 0 & 0 & 37.5 & 33.3 & 0 & 14.3 \\
\hline
\end{tabular}

Table 3. Validation results for SMADI.

If we look at the annual matches, we observe that very good results are obtained for years 2010 to 2013, both regarding extension (over $70 \%$ ) and extremes (over $60 \%$ ), whereas poorest results are obtained for year 2014 ( $25 \%$ for both metrics). It is difficult to explain such a difference in SMADI performance, but, as we show in the subsequent analysis, 2014 is the year with the poorest performance also for SPI and SPEI indices.

The metric Extreme_33 allows gaining insight into the impact of the intensity of drought events in the detection, since they require that at least $33 \%$ of the analysed area is detected as extreme by SMADI to be considered as a match (SMADI $\geq 4$ ). In this line, years 2012 and 2013 (3 and 4 extreme_33 events, over $1 / 3$ of the total number of events) could be considered as being drier than the rest of the years that do not show any event so extreme.
Table 4 summarizes the validation results for SPI. Overall, we can see that SPI has also reasonably good detection capabilities for the agricultural drought events, but it leads to lower values than SMADI in all the analysed metrics (matches, both extreme metrics, and duration).

\begin{tabular}{|c|c|c|c|c|c|c|}
\hline & 2010 & 2011 & 2012 & 2013 & 2014 & Total \\
\hline $\begin{array}{l}\text { Drought } \\
\text { events }\end{array}$ & 6 & 19 & 8 & 12 & 4 & 49 \\
\hline $\begin{array}{c}\text { SPI } \\
\text { matches }\end{array}$ & 6 & 15 & 7 & 8 & 1 & 37 \\
\hline $\begin{array}{l}\% \text { correct } \\
\text { matches }\end{array}$ & 100 & 78.9 & 87.5 & 66.7 & 25 & 75.5 \\
\hline$\%$ duration & 19.1 & 18.7 & 15.3 & 12.8 & 8.3 & 16.6 \\
\hline $\begin{array}{c}\text { SPI } \\
\text { Extreme_0 }\end{array}$ & 1 & 7 & 2 & 6 & 1 & 17 \\
\hline $\begin{array}{c}\% \text { SPI } \\
\text { Extreme_0 }\end{array}$ & 16.7 & 36.8 & 25 & 50 & 25 & 34.7 \\
\hline $\begin{array}{c}\text { SPI } \\
\text { Extreme_33 }\end{array}$ & 0 & 1 & 0 & 1 & 0 & 2 \\
\hline $\begin{array}{c}\% \text { SPI } \\
\text { Extreme_33 }\end{array}$ & 0 & 5.3 & 0 & 8.3 & 0 & 4.1 \\
\hline
\end{tabular}

Table 4. Validation results for SPI.

Considering the year-by-year analyses, the percentage of correct matches is higher for SPI in 2010, lower in 2012 and 2013, and the same than SMADI in 2011 and 2014. Extreme 0 values are lower for SPI than for SMADI for every year except 2014, and duration values are lower for SPI than for SMADI for every year. Interestingly, even the highest duration value of SPI is lower than the lowest duration value for SMADI. These differences could be due to at least three factors: first, SPI takes into account only precipitation deficit, which does not necessarily propagate to a deficit on soil moisture or plant available water leading to crop failure. For instance, during an intense drought, one month of normal rainfall would give a SPI 0 (and thus would not be included in the duration calculation), but could not be enough to overcome soil dryness and/or vegetation hydric stress.

Second, spatial resolution is different between the two indices. SMADI resolution is $0.05^{\circ}$, a tenth of the $0.5^{\circ}$ at which SPI is provided. Besides, SPI is calculated using precipitation data from meteorological stations that are further apart than $0.5^{\circ}$; in order to obtain a spatially complete map, point SPI calculations are interpolated with techniques of varying complexity that inevitably add errors to the spatialized measurements and, ultimately, to the index.

Third, the temporal resolutions at which SMADI and SPI are computed are different. Even though time conditions for establishing a match are nearly the same (28 days vs. a month respectively), the fact that each SMADI calculation is an integration of conditions over 14 days may be giving it an improved sensibility, especially at the beginning and ending of drought events, over the monthly calculation used for SPI. Still, 
calculation of SPI for shorter periods than a month led to unstable results in a previous study carried out in our study region (Podestá et al., 2016) and therefore was not considered in this work.

Validation results for SPEI shown in Table 5 are in between the ones obtained for SMADI and the ones obtained for SPI.

\begin{tabular}{|l|c|c|c|c|c|c|}
\hline & 2010 & 2011 & 2012 & 2013 & 2014 & Total \\
\hline $\begin{array}{l}\text { Drought } \\
\text { events }\end{array}$ & 6 & 19 & 8 & 12 & 4 & 49 \\
\hline $\begin{array}{l}\text { SPEI } \\
\text { matches }\end{array}$ & 4 & 15 & 7 & 12 & 2 & $\mathbf{4 0}$ \\
\hline $\begin{array}{l}\text { \% correct } \\
\text { matches }\end{array}$ & 66.7 & 78.9 & 87.5 & 100 & 50 & $\mathbf{8 1 . 6}$ \\
\hline $\begin{array}{l}\% \text { duration } \\
\text { SPEI }\end{array}$ & 22.6 & 21.2 & 18.4 & 22.7 & 14.6 & $\mathbf{2 1}$ \\
\hline $\begin{array}{l}\text { Extreme_0 } \\
\text { Extreme_0 }\end{array}$ & 0 & 36.8 & 12.5 & 58.3 & 0 & $\mathbf{3 0 . 6}$ \\
\hline $\begin{array}{l}\text { SPEI SPEI } \\
\text { Extreme_33 }\end{array}$ & 0 & 10.5 & 0 & 16.7 & 0 & $\mathbf{8 . 2}$ \\
\hline $\begin{array}{l}\text { Extreme_33 } \\
\text { SPEI }\end{array}$ & 2 & 0 & 2 & 0 & $\mathbf{4 5}$ \\
\hline
\end{tabular}

Table 5. Validation results for SPEI.

We can see that metrics obtained for SPEI are close to the ones for SMADI, except for duration and extreme 33 metrics, where SMADI shows greater performance. Compared to SPI, SPEI leads to higher values in all metrics except for extreme_0.

Since the spatial and temporal resolution are the same for SPI and SPEI, the improvement on SPEI matches and duration metrics should be due to the fact that SPEI also includes potential evapotranspiration alongside precipitation data. However, it does not include information on soil moisture and actual vegetation status and that is probably why validation results are still far below the ones obtained for SMADI, which does take into account these two factors (the former in a direct way, the latter using NDVI as a proxy).

\section{CONCLUSION AND FUTURE WORK}

In this work we have analysed two approaches for the detection of drought events that were severe enough as to be declared "Agrarian Emergency" by the Argentinean Ministry of Agriculture: the first approach proposes the novel use of remotely sensed information on soil moisture and vegetation status (SMADI), and the second or "classic" approach consists of including data from meteorological stations (precipitation in SPI, precipitation and evapotranspiration in SPEI). Results indicate that SMADI allows for greater agricultural drought detection capabilities: it was able to recognize more than $83 \%$ of the registered emergencies, correctly classifying $75 \%$ of them as extreme droughts, and outperforming SPI and SPEI in all the analysed metrics.

The distinct performance of SMADI shown in this work confirms the results obtained in previous studies at regional (Sánchez et al., 2016) and global scales (Sánchez et al., 2018) and supports its use as a near real time information layer for the analysis of hydric conditions of any given area within Argentina, in order to determine if a declaration of Agrarian Emergency is needed.

Future work will be directed towards the analysis of false positive alarms that may be triggered using the same three indices. This is needed for a full characterization of the indices' ability to detect agricultural drought in the study region.

\section{ACKNOWLEDGEMENTS}

This work was supported by Argentinean Agencia Nacional de Promoción Científica y Tecnológica (ANPCyT) project PICT 2017-1406 and by the Spanish Ministry of Science, Innovation and Universities and the European Regional Development Fund (ERDF, EU) projects ESP2017-89463-C3-3-R and RTI2018096765-A-100. SPEI and SPI index data is freely available and was downloaded from http://www.crcsas.org/es/monitoreo sequias.php. SMADI global data for the study period was calculated by the authors and shared freely at http://doi.org/10.5281/zenodo.3247649.

\section{REFERENCES}

Barcelona Expert Center (2019). BEC-SMOS-0003-PD-Land. Products Description, BEC 2019-7-31. Issue 1.0. Available online at: http://bec.icm.csic.es/doc/BEC-SMOS-0003-PDLand.pdf. Last visited: 21/10/2019.

Barella-Ortiz, A, and Quintana-Seguí, P, 2018: Evaluation of drought representation and propagation in Regional Climate Model simulations over Spain, Hydrol. Earth Syst. Sci. Discuss., 1-32. 10.5194/hess-2018-603.

Carlson, TN, Gillies, RR and Perry, EM, 1994. A method to make use of thermal infrared temperature and NDVI measurements to infer surface soil water content and fractional vegetation cover. Remote Sensing Reviews, 9, 161-173.

CRC-SAS, 2019. Centro Regional del Clima para el Sur de América del Sur (Regional Climate Center Network for Southern South America). URL: http://www.crcsas.org/es/monitoreo sequias.php. Last visited: 21/10/2019

Foley, JA, Ramankutty, N, Brauman, KA, Cassidy, ES, Gerber, JS, Johnston, M, Mueller, ND, O'Connell, C, Ray, DK, West, PC, Balzer, C, Bennett, EM, Carpenter, SR, Hill, J, Monfreda, C, Polasky, S, Rockström, J, Sheehan, J, Siebert, S, Tilman, D, Zaks, DP. 2011. Solutions for a cultivated planet. Nature, 478:337 EP

IGN, 2019. Instituto Geográfico Nacional. URL: http://www.ign.gob.ar/NuestrasActividades/Geografia/DatosAr gentina/LimitesSuperficiesyPuntosExtremos . Last visited: $21 / 10 / 2019$ 
IPCC: Climate change 2014: Synthesis Report. Contribution of Working Groups I, II and III to the Fifth Assessment Report of the Inter- governmental Panel on Climate Change [Core Writing Team, RK Pachauri and LA Meyer (eds.)]. IPCC, Geneva, Switzerland, $151 \mathrm{pp}, 2014$

Keyantash, J, and National Center for Atmospheric Research Staff (Eds). Last modified 07 Aug 2018. The Climate Data Guide: Standardized Precipitation Index (SPI). Retrieved from https://climatedataguide.ucar.edu/climate-data/standardizedprecipitation-index-spi.

Kogan, FN, 1990. Remote sensing of weather impacts on vegetation in nonhomogeneous areas. Int. J. Remote Sens., 11, pp. $1405-1419$.

Kogan, FN, 1995. Application of vegetation index and brightness temperature for drought detection. Adv. Space Res., 15, pp. 91100.

Lema, D, Amaro, IB, Pace, I. 2018. Impacto de la sequía sobre los márgenes brutos esperados de soja y maíz en la región pampeana: ¿En qué situación los aumentos de precios compensarían las pérdidas de rendimientos? Instituto de Economía - INTA, pp: 1-9, available online at https://inta.gob.ar/sites/default/files/inta cicpes instdeeconomia lema impacto sequia margenes brutos 0.pdf. Last accessed: 27-Oct-2019.

MAGyP, 2019. Ministerio de Agricultura, Ganadería y Pesca. URL:https://www.agroindustria.gob.ar/sitio/areas/d eda/resoluc iones/. Last visited: $21 / 10 / 2019$.

Martínez-Fernández, J, González-Zamora, A, Sánchez, N, Gumuzzio, A, and Herrero-Jiménez, CM. 2016. Satellite soil moisture for agricultural drought monitoring: Assessment of the SMOS derived Soil Water Deficit Index. Remote Sens. Environ., $177,277-286$.

McKee, TB, Doesken, NJ, and Kleist, J. 1993. The relationship of drought frequency and duration of time scales. Eighth Conference on Applied Climatology. American Meteorological Society, Anaheim CA (USA), pp. 179-186.

Mishra, A, Vu, T, Veettil, AV, and Entekhabi, D. 2017 Drought monitoring with soil moisture active passive (SMAP) measurements. J. Hydrol. 552, 620-632.

Pablos, M, Martínez-Fernández, J, Sánchez, N, and GonzálezZamora, Á. Temporal and Spatial Comparison of Agricultural Drought Indices from Moderate Resolution Satellite Soil Moisture Data over Northwest Spain. Remote Sens. 2017, 9, 1168 .

Pisani-Claro, N, and Miazzo, D. 2017. El campo argentino en números. FADA: Fundación Agropecuaria para el Desarrollo Argentino, pp: 1-10. Available online at http://agro.unc.edu.ar/ economia/wpcontent/uploads/2018/03/El-campo-argentino-enn\%C3\%BAmeros-2017.pdf. Last accessed: 27-Oct-2019.

Podestá, G, Skansi, M, Herrera, N, and Veiga, H. 2016. Descripción de índices para el monitoreo de sequía meteorológica implementados por el Centro Regional del Clima para el Sur de América del Sur. Serie Reportes Técnicos Reporte Técnico CRC-SAS-2015-001. Available online at: http://www.crc-

sas.org/es/content/monitoreo/reporte sequias.pdf. Last visited: 23/10/2019.

Sánchez, N, González-Zamora, A, Piles, M, and MartínezFernández, J. 2016. A New Soil Moisture Agricultural Drought Index (SMADI) Integrating MODIS and SMOS Products: A Case of Study over the Iberian Peninsula. Remote Sens. 8, 287.

Sanchez, N, González-Zamora, A, Martínez-Fernández, J, Piles, M, and Pablos, M. 2018. Integrated remote sensing approach to global agricultural drought monitoring. Agricultural and Forest Meteorology, 259, 141-153.

Scaini, A, Sánchez, N, Vicente-Serrano, SM, and MartínezFernández, J. 2015. SMOS-derived soil moisture anomalies and drought indices: a comparative analysis using in situ measurements. Hydrol. Process., 29, pp. 373-383.

SMN, 2019. Servicio Meteorológico Nacional. URL: https://www.smn.gob.ar/clima/atlasclimatico. Last visited: $21 / 10 / 2019$

Vicente-Serrano, SM, Beguería, S, and López-Moreno, JI. 2010. Multi-scalar drought index sensitive to global warming: The Standardized Precipitation Evapotranspiration Index-SPEI. Journal of Climate and Applied Meteorology, 23, 1696-1718. 